\title{
Human Heredity Now and in the Future
}

\author{
MATTHEW MESELSON \\ Department of Molecular and Cellular Biology Harvard University, Cambridge, \\ MA, USA. Email: msmeselson@gmail.com
}

The distinctive human characteristic of curiosity, once liberated from belief in supernatural causes of natural phenomena, has led with increasing speed to the brink of a world in which humanity will increasingly direct its own genetic endowment, raising the question of what we most value in being human and how to keep faith with it.

The rate of change has increased so much that our imagination can't keep up. (C.P. Snow, 1959) ${ }^{1}$

While it can confidently be said that the human genetic endowment will not change rapidly, it can be said with equal confidence that it will change. The biblical idea of fixed species was already in disrepute and the occurrence of biological evolution throughout nature was widely recognized well before the time of Charles Darwin and Alfred Russel Wallace. Their great insight, arrived at independently and first published in 1858, was that evolution is driven by natural selection acting on heritable variation: that heritable characteristics conferring an increase in reproductive success will tend to increase within a population, giving rise over long time spans to what we recognize as new varieties and eventually new species and higher order taxa. This simple idea appears not to have entered the evolutionary thinking of anyone before Darwin and Wallace. With certain refinements, it remains a central part of evolution science today.

But no sound theory of evolution could be developed until 1900, when Mendel's great paper of 1866, ignored for 34 years even though widely available, was finally recognized by biologists. Before that, it was believed that the hereditary characteristics of parents blend in the production of offspring. This meant that a beneficial variation arising in an individual member of a large population would be diluted out in successive generations to the point where the benefit to any individual would become negligible and unrecognizable to natural selection. Mendel showed that the units of heredity are discrete and do not blend. Without blending, a population can maintain a supply of variation on which selection may act. 
After 1900 and after bitter dispute between Mendelians and non-Mendelians loyal to an earlier view of the relation between variation and evolution, progress in understanding evolution and heredity was rapid. This achieved a far-reaching synthesis, explaining many of the phenomena of evolution and heredity in terms of the rules of formal genetics and, at a different but complementary level, in terms of the behaviour of chromosomes in meiosis, the specialized cell divisions preceding the production of eggs and sperm. This provided a unifying outlook and a guide for experimentation that extended into nearly all fields of biology. By the late 1930s classical genetics was essentially complete. Complete in the sense that a college course could even now be taught from a textbook published then.

The second great wave of advances in genetics was the rise of molecular biology, resting on structural chemistry and biochemistry. When I was a college student at the University of Chicago just after the Second World War, I wondered how atoms of the ordinary elements could be put together in complex structures, the genes, so as to be replicated exactly in each generation save for infrequent mutations that are then also replicated exactly. At that time, there was concern that genes might be too dynamic and delicate to study by ordinary chemical methods. They might fall apart in the course of any attempt to isolate and study them. It turned out, of course, the other way around. DNA, the principal carrier of genetic information, is extremely stable to diverse laboratory manipulations. This was not altogether unexpected. Life depends on maintaining the fidelity of genetic information, and geneticists had shown that mutation of individual genes is very infrequent. The stability of DNA and of various molecules and molecular complexes involved in its replication and phenotypic expression made possible the quite simple experiments that underlie our present understanding of the molecular basis of heredity.

Today, high school science students learn about the self-complementary double helical structure of DNA; the way in which it replicates; how the genetic information is encoded in long sequences of its four constituent nucleotides, based on adenine, guanine, thymine and cytosine; the way DNA is transcribed into RNA; and the way the transcribed information is translated from RNA, according to the genetic code, by small RNA molecules called adapters, into sequences of amino acids that constitute proteins.

All this and considerably more regarding the molecular basis of the storage, replication and expression of genetic information and the way in which the genetic program guides morphology is now known. The immense progress in biology since the fundamental discovery 180 years ago that all plants and animals are made up of cells and cell products has essentially answered the question of how life works. And knowing the detailed mechanism of heredity has placed biologists in a position to manipulate it.

Early experiments, going back to the 1940s, had already shown the possibility of replacing one segment of DNA in a cell with another, at least in bacteria. Nevertheless, in 1970, Jacques Monod, Nobel Prize winner in Physiology or Medicine, was able to write in his book Necessity and Chance:

Coping with these dangers [he was talking about a possible deterioration in the human genetic heritage] there are occasional promises of remedies expected from the current advances in molecular genetics. This illusion, spread about by a few 
superficial minds, had better be disposed of. No doubt it will be possible to palliate certain genetic flaws, but only in the affected individual, not in his posterity. Not only does modern molecular genetics give us no means whatsoever for acting upon the ancestral heritage in order to improve it with new features, but it reveals the vanity of any such hope. ${ }^{2}$

Yet even then there were crude methods by which segments of DNA could be added to animal genomes, including, at least in principal, the genomes of human somatic and germline cells. But an early attempt at human somatic cell gene therapy had disastrous consequences, causing interest in it to evaporate, as seen in the abrupt decline in the number of published papers after $2007 .{ }^{3}$ Only ten years later, in 2017, did the US Food and Drug Administration give its approval to the use in medical practice of a much refined form of somatic cell gene therapy. Called CAR-T, it is a procedure in which immune cells are harvested from a patient's blood and treated with a virus designed to integrate into the genome or otherwise introduce into the cells a segment of DNA that reprograms them to attack specific kinds of cancer cells. The reprogramed immune cells are then returned to the patient's circulation. The two forms of CAR-T gene therapy approved so far by the US Food and Drug Administration for clinical use are directed against particular forms of leukaemia and lymphoma.

In the same year, a far more precise and versatile tool for gene therapy called CRISPR/CAS9 was approved by the Recombinant DNA Advisory Committee of the US National Institutes of Health for treatment of a rare congenital degenerative disease of the retina. Approval for clinical trial is expected to follow soon. In this case, injection into the retinal region of a virus carrying the CRISPR/CAS9 system engineered to delete a section of a gene carrying the mutation responsible for the malady restores normal vision. CRISPR/CAS9 and its variants provide a remarkably simple way to cut DNA within a cell at any desired place and, with great precision, either delete a segment, add a segment or replace one segment of DNA with another. Its versatility, simplicity and precision have already led to many successful applications in genetically engineering the germ line of a wide variety of non-human organisms, including applications to improve crop plants and livestock. $^{4}$

Beyond applications affecting only the treated patient, a potentially much more consequential application of CRISPR/CAS9 technology would be in the alteration of the human germ line, something Monod half a century ago thought impossible. Human germline editing with CRISPR/CAS9 has so far been applied only to embryos in laboratory experiments to replace disease genes with their normal versions without allowing the modified embryos to develop beyond an early stage.

The potential of CRISPR/CAS9 for human germline modification has occasioned vigorous discussion, with views ranging from objection to it under any circumstances, to acceptance only when intended to remove or replace a deleterious gene, to the view that there is a moral imperative not only to prevent the inheritance of genetic disease but to modify the germline in any way that improves the health of the child and its chances for a good life. ${ }^{5-9}$ 
Despite the great potential of CRISPR/CAS9 and its refinements for therapeutic modification of the human germline, it is sometimes overlooked in discussions of its promise that, aside from possible non-medical reservations, the combination of preimplantation diagnosis (PID) and artificial insemination already provides a readily available procedure for preventing the inheritance of deleterious genes. In this procedure, after hormone treatment to induce multiple ovulation, several eggs are harvested, fertilized in vitro and allowed to develop to an early stage. A cell from each embryo is then tested for the presence of the undesirable gene. If one of the prospective parents carries a single copy of it and the other parent is entirely normal, half of the embryos on average should be normal. Typically, several embryos are tested at the same time and only if found to be free of the undesirable gene is one of them implanted for a normal pregnancy. Only in the exceedingly rare case in which one or the other of the prospective parents is homozygous for the deleterious gene is the procedure incapable of producing an embryo not carrying it. Even then, as is not uncommon, if acceptable to the prospective parents, PID can be conducted with embryos produced with eggs or sperm from an unaffected donor. In other words, in the great majority of cases in which it is desired to prevent the inheritance of a deleterious gene, there already exists a well-established method that does not involve modification of the germ line. ${ }^{6}$

Nevertheless, with CRISPR/CAS9 and its variants we are now set on a path that is likely to lead to taking charge of our own evolution. Not now, not soon, but eventually. Unlike PID and artificial fertilization, it can not only prevent the inheritance of deleterious genes, it can add enhancements of ordinary human qualities and even altogether novel genetic features. Unlike replacing a mutant human gene with a normal human gene, the addition of enhancements and novel features will first require careful experiments to make sure that doing so does not result in harmful gene interactions, a form of what is called epistasis. Another problem arises in attempting to affect, whether for eradication of disease or for enhancement, conditions or characteristics that are determined not by just one or a few known genes but by many, when the identity of the relevant genes and how they individually contribute to the character of interest are unknown. But given time and adequate research effort these problems are inherently solvable.

In a quite different area with similarly great potential for affecting the future of humanity is the already advanced design and engineering aimed at exploration and human settlement of the planet Mars. ${ }^{10}$ There, human society will surely develop in ways different from what has gone on here on Earth. And with an initially small and highly selected founder population, conditions of life quite different from those on earth, and the likelihood of active intervention in what Monod called the ancestral heritage, human heredity would surely be affected, although in ways that cannot be foreseen.

Yet another development likely to affect the human genetic heritage in ways impossible to foretell may be seen in the advent of advanced artificial intelligence. Not simply machines that guide ordinary human tasks but powerful machines that guide or even make decisions affecting how society is organized, how other technologies, including biotechnology, including genetic modification are used. 
Perhaps all that can be said now is that a most fundamental human characteristic curiosity, the demand to know, liberated from supernatural thinking, will continue to carry us into unpredictable futures, hopefully benign. The prospect of human intervention in human evolution, even if only theoretical for now, extraterrestrial settlement, likely to begin within a generation, and the advent of advanced artificial intelligence, should cause us to be increasingly drawn to study human origins, the sources of civilization, and the humanities in order to know what humanity is, in order to keep faith with what in it is essential.

\section{References}

1. C.P. Snow (1959) The Two Cultures and the Scientific Revolution (The Rede Lecture, 1959) (Cambridge, UK: Cambridge University Press).

2. J. Monod (1971) Chance and Necessity: Essay on the Natural Philosophy of Modern Biology (New York: Knopf).

3. J.M. Wilson (2009) A history lesson for stem cells. Science, 324, pp. 727-728.

4. J.A. Doudna and S.H. Sternberg (2017) A Crack in Creation: Gene Editing and the Unthinkable Power to Control Evolution (Boston: Houghton Mifflin Harcourt).

5. D. Baltimore, P. Berg, M. Botchan, D. Carroll, R. Alta Charo, G. Church, J.E. Corn, G.Q. Daley, J.A. Doudna, M. Fenner, H.T. Greely, M. Jinek, G.S. Martin, E. Penhoet, J. Puck, S.H. Sternberg, J.S. Weissman and K.R. Yamamoto (2015) Biotechnology. A prudent path forward for genomic engineering and germline gene modification. Science, 348, pp. 36-38.

6. National Academies of Sciences, Engineering, Medicine, and Committee on Human Gene Editing: Scientific, Medical, Ethical Considerations (2017) Human Genome Editing: Science, Ethics, and Governance (Washington, DC: National Academies Press).

7. E. Lanphier, F. Urnov, S.E. Haecker, M. Werner and J. Smolenski (2015) Don't edit the human germ line. Nature, 519, pp. 410-411.

8. K.E. Ormond, D.P. Mortlock, D.T. Scholes, Y. Bombard, L.C. Brody, W.A. Faucett, N.A. Garrison, L. Hercher, R. Isasi, A. Middleton, K. Musunuru, D. Shriner, A. Virani and C.E. Young (2017) Human germline genome editing. The American Journal of Human Genetics, 101, pp. 167-176.

9. J. Savelescu (2015) The moral imperative to continue gene editing research in human embryos. Protein and Cell, 6, pp. 476-479.

10. E. Musk (2017) Making humans a multi-planetary species. New Space, 5, pp. 46-62.

\section{About the Author}

Matthew Meselson is Professor in the Department of Molecular and Cellular Biology at Harvard University. He received a $\mathrm{PhB}$ degree from the University of Chicago in 1951 and a PhD from the California Institute of Technology in 1957. He was Assistant Professor of Physical Chemistry at CalTech until joining the Harvard faculty in 1960, where he teaches and conducts research in molecular genetics. Since 1963 he has had an interest in the abolition of biological and chemical weapons. 